\title{
Minute Lung Carcinoma Associated with Focal Honeycombed Lesion
}

\author{
SHINZO TAKAMORI, AKIHIRO HAYASHI, YASUHIRO TERAZAKI, KEISUKE MIWA, \\ MARI FUKUNAGA, HISASHI NAKAMURA, OSAMU NAKASHIMA* \\ AND KAZUO SHIROUZU
}

Departments of Surgery and Pathology*, Kurume University School of Medicine,

Kurume 830-0011, Japan

\begin{abstract}
Summary: We report a case of minute lung carcinoma that developed in a focal honeycombed lesion in the right lung. A 70-year-old man presented hemosputum, and a cytological examination result was at class IV. A right lower lobectomy of the lung was performed. Microscopically, the thickened alveolar wall revealed tumor cells indicating a minute carcinoma, and showed squamous hyperplasia, metaplasia, and dysplasia, with the carcinoma in the distal airway epithelium. This peripheral lung carcinoma in a focal honeycombed lesion demonstrated the various stages of multistep carcinogenesis, which is recognized in hilar type squamous cell carcinoma. To date, the association between a honeycombed lesion and lung cancer has been poorly described. Here we have presented clear evidence of the association of this carcinoma with the honeycombed lesion.
\end{abstract}

Key words lung carcinoma, honeycombed lesion, carcinogenesis

\section{INTRODUCTION}

Squamous cell carcinoma is one of the most frequently occurring lung cancer, and about half of arise in the major bronchus. The five-year survival rate of patients with early squamous cell carcinoma of the hilar type is over $90 \%$, but this neoplasm is frequently found to be associated with second squamous cell carcinoma of the bronchus. T1N0M0 squamous cell carcinoma of the peripheral type is not always associated with a good prognosis, and shows a 5-year survival rate of about 75\% [1,2]. Early squamous cell carcinoma of peripheral type should be considered as T1N0M0 with a tumor smaller than $2 \mathrm{~cm}$ in diameter, because those cases show a more than $90 \%$ 5-year survival rate. However, such small carcinoma is infrequently encountered, probably due to the rather rapid growth of squamous cell carcinoma compared to that of adenocarcinoma. The various stages involved in the multistep carcinogenesis of squamous cell carcinoma in situ have been recognized in the epithelium of the major bronchi, which was described originally in cervical carcinoma of the uterus [3]. This concept of multistep carcinogenesis has not yet been seen in peripheral squamous cell carcinoma of the lung. Idiopathic pulmonary fibrosis (IPF), one of interstitial lung disease, has been considered to be associated with a high risk for lung cancer. Although a honeycombed lesion is sometimes seen in interstitial lung disease, the association between a honeycombed lesion and lung cancer has been poorly described. Here we report a peripheral minute lung carcinoma presenting various stages of multistep carcinogenesis, which was associated with focal honeycombed lesion in the lung.

\section{CASE REPORT}

A 70-year-old man presented hemosputum. A chest X-ray showed no abnormality, and computed tomography showed an abnormal shadow in the right lower lobe of the lung with no lymphadenopathy (Fig. 1). The abnormal shadow was a subpleural focal honeycombed lesion of $2.0 \times 1.8 \mathrm{~cm}$ in diameter 
showing cavitation with spiculation. A bronchofiberoptic examination found no abnormality in the endobronchial lumen. Sputum cytology obtained by bronchofiberscopy classified the sputum as class IV. The pulmonary function showed a mild obstructive disorder with $\mathrm{FEV}_{1.0}$ at $1.67 \mathrm{~L}$ and $\mathrm{FEV}_{1.0 \%}$ at $50.3 \%$. The laboratory hematological and chemistry values were all within normal limits, except for an elevation of squamous cell carcinoma antigen at 1.9 $\mathrm{ng} / \mathrm{ml}$ (normal: below $1.0 \mathrm{ng} / \mathrm{ml}$ ). A right lower lobectomy without lymph node dissection was performed.

A low-power view of the resected lung showed emphysematous and the subpleural honeycombing lesion with cavitation, wall thickening, and spiculation (Fig. 2). Microscopically, the epithelial cells showed hyperplasia, metaplasia (Fig. 3), dysplasia

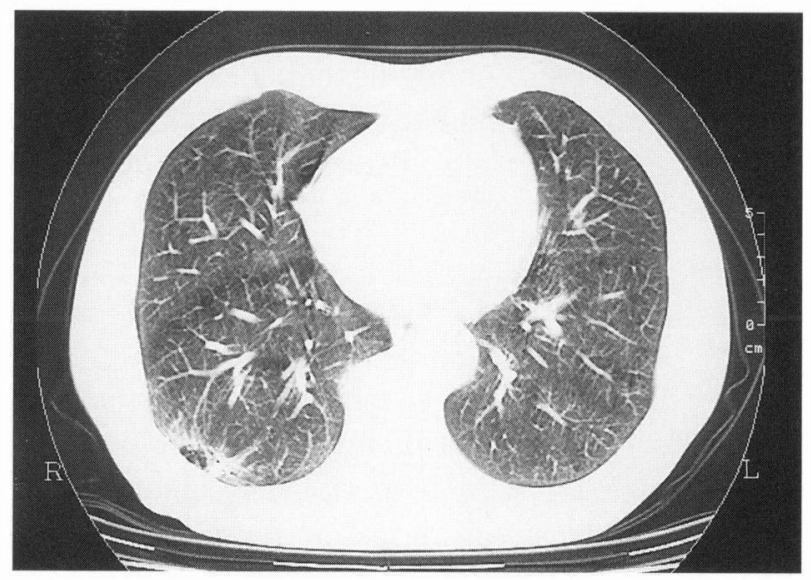

Fig. 1. CT scan showing a subpleural abnormal area with cavitation and speculation in the right lower lobe of the lung.
(Fig. 4), and the carcinoma (Fig. 5) in the thickening wall. The pathological diagnosis was microcarcinoma in the distal airway epithelium.

The postoperative course was uneventful, and the squamous cell carcinoma antigen decreased to within

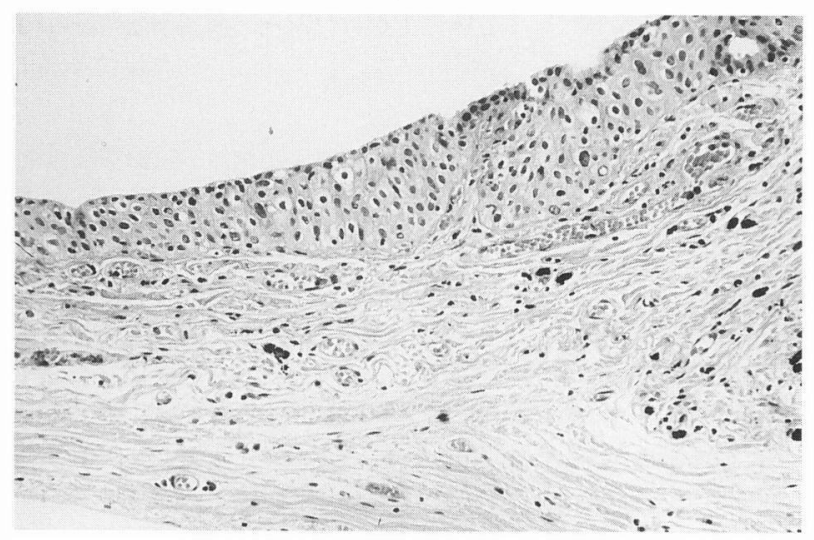

Fig. 3. Squamous metaplasia in the distal airway epithelium. (HE, $\times 50)$

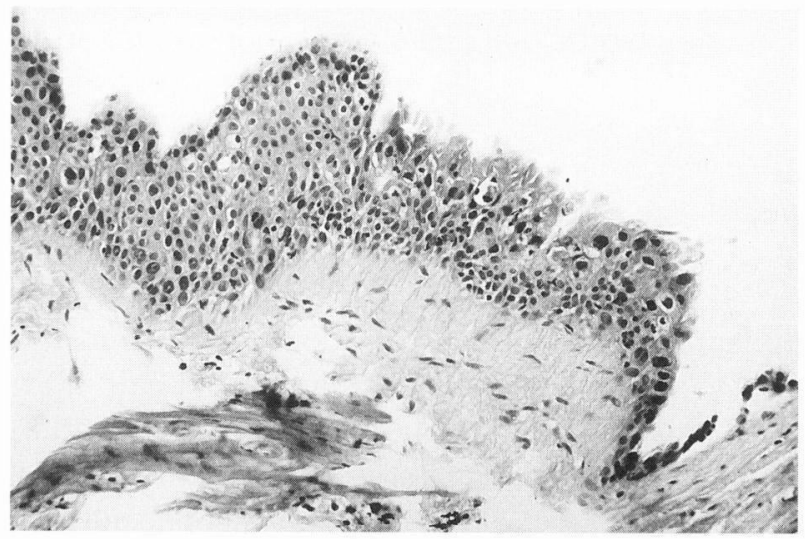

Fig. 4. Squamous dysplasia in the distal airway epithelium. $(\mathrm{HE}, \times 50)$

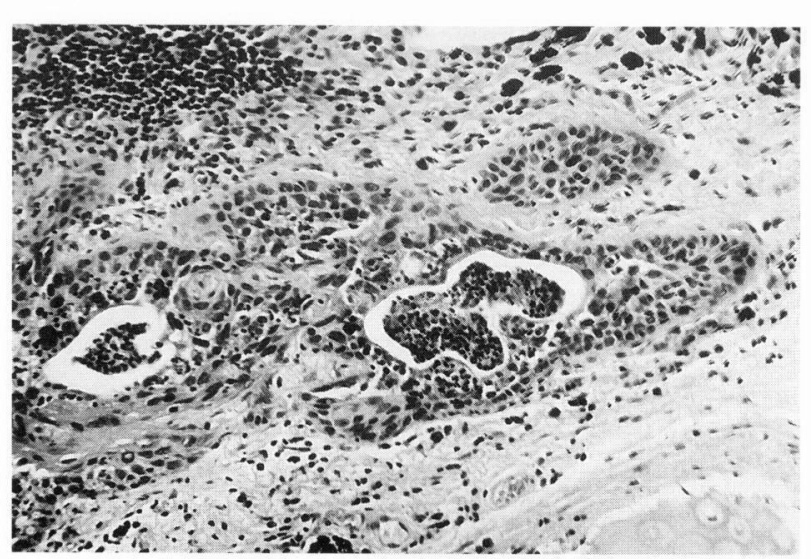

Fig. 5. Squamous cell carcinoma nest in the thickened wall of the cavity. (HE, $\times 100)$ 
the normal range. The patient is alive 6 years after the operation with no recurrence in carcinoma and no development of the honeycombed lesion in the lung.

\section{DISCUSSION}

It is well known that lung cancer occurs more frequently in patients with IPF than in those without [4-8]. Mizushima et al. presented an exhaustive review of the Japanese literature on IPF patients who have developed lung cancer [9]. Their primary intent was to identify the clinical and pathological characteristics of multicentric bronchogenic carcinoma, of both synchronous and metachronous varieties in this population. This was accomplished by comparison of the multicentric tumor group, with that of IPF patients with cancer of a solitary lung, and of a massive histologic group of bronchogenic carcinoma of all types in Japanese patients. They found that the features characteristics to synchronous multiple lung cancer in patients with IPF were (1) male; (2) smoking; (3) small cell carcinoma histologic type; (4) lower lobe; and (5) peripheral type. And all such patients showed a high rate of occurrence. Our patient was a male smoker and his solitary lung cancer was a peripheral squamous cell carcinoma in the right lower lobe. Although he is alive to date 6 years after the operation with no recurrence, further follow-up is needed.

Hironaka and Fukayama reported the relation between IPF and risk to lung carcinoma [10]. They reviewed the clinical features of IPF autopsy cases with or without lung carcinoma, and compared the morphology and cell kinetics of metaplastic epithelia in the honeycombed area. They concluded that the quantitative predominance of squamous metaplasia in the honeycombed area may in fact not be the actual precursor of lung carcinoma, but might reflect a constitutional susceptibility of IPF patients to develop a lung carcinoma. In our case, a peripheral lung carcinoma in a focal honeycombed lesion showed squamous hyperplasia, metaplasia, and dysplasia, with the carcinoma in the distal airway epithelium. We found a clear association between the honeycombed lesion and the carcinoma.

Mutations in the tumor suppressor gene p53 lead to accumulation of the mutated p53 protein subsequent production of autoantibodies against p53 protein, which are also detected in lung cancer. Oshikawa and Sugiyama reported that p53 mutations occurred frequently in IPF, resulting in a high prevalence of lung cancer [11]. Another report by Kawasaki et al. suggested that p53 gene alterations played an important role in the early stages of lung carcinogenesis in patients with IPF [12]. Further investigations including molecular analyses are necessary to clarify the relationship between the honeycombed lesion and lung cancer.

\section{REFERENCES}

1. Shimosato Y. Pulmonary neoplasms. In: Diagnostic Surgical Pathology, 2nd edn., ed. Sternberg SS, Raven Press, New York, pp 1045-1093, 1994.

2. Adebonojo SA, Bowser AN, Moritz DM, and Corcoran PC. Impact of revised stage classification of lung cancer on survival: a military experience. Chest 1999; 115:1507-1513.

3. Auerbach O, Stout AP, and Hammond EC. Changes in bronchial epithelium in relation to cigarette smoking and in relation to lung cancer. N Engl J Med 1961; 265:253266.

4. Crystal RG, Fulmer JD, Roberts WC, Moss ML, Line BR et al. Idiopathic pulmonary fibrosis. Clinical, histologic, radiographic, physiologic, scintigraphic, cytologic, and biochemical aspects. Ann Intern Med 1976; 85:769788.

5. Fraire AE, and Greenberg SD. Carcinoma and diffuse interstitial fibrosis of lung. Cancer 1973; 31:1078-1086.

6. Turner-Warwick M, Lebowitz M, Burrows B, and Johnson A. Cryptogenic fibrosing alveolitis and lung cancer. Thorax 1980; 35:496-499.

7. Kuhara H, Wakabayashi T, Kishimoto H, Morishita M, Suzuki $\mathrm{T}$ et al. Synchronous bilateral double primary lung cancer associated with diffuse interstitial fibrosing pneumonitis (DIFP). Acta Pathol Jpn 1984; 34:617-629.

8. Nagai A, Chiyotani A, Nakadate T, and Konno K. Lung cancer in patients with idiopathic pulmonary fibrosis. Tohoku J Exp Med 1992; 167:231-237.

9. Mizushima Y, and Kobayashi M. Clinical characteristics of synchronous multiple lung cancer associated with idiopathic pulmonary fibrosis: a review of Japanese cases. Chest 1995; 108:1272-1277.

10. Hironaka M, and Fukayama M. Pulmonary fibrosis and lung carcinoma: a comparative study of metaplastic epithelia in honeycombed areas of usual interstitial pneumonia with or without lung carcinoma. Pathol Int 1999; 49:1060-1066.

11. Oshikawa K, and Sugiyama Y. Serum anti-p53 autoantibodies from patients with idiopathic pulmonary fibrosis associated with lung cancer. Respir Med 2000; 94:10851091.

12. Kawasaki H, Ogura T, Yokose T, Nagai K, Nishiwaki Y et al. p-53 gene alteration in atypical epithelial lesions and carcinoma in patients with idiopathic pulmonary fibrosis. Hum Pathol 2001; 32:1043-1049. 